\title{
Commentary \\ Recently published papers: Renal replacement therapy: which route and how much? Intracerebral haematomas: does the size matter? $\beta$ blockers and steroids: will we ever know?
}

Vlad Kushakovsky and Richard Venn

Department of Critical Care, Worthing Hospital, Lyndhurst Road, Worthing BN11 2DH, UK

Corresponding author: Vlad Kushakovsky, vladku@doctors.org.uk

Published: 14 August 2008

This article is online at http://ccforum.com/content/12/4/172

(c) 2008 BioMed Central Ltd

Critical Care 2008, 12:172 (doi:10.1186/cc6968)

\begin{abstract}
Femoral access for renal replacement therapy appears to have a similar infection rate to jugular access. High-intensity renal support does not seem to improve mortality or length of hospital stay. Acute kidney injury as defined by Acute Kidney Injury Network predicts increased hospital mortality. Recombinant factor Vlla reduces growth of volume of intracerebral haematoma but does not affect clinical outcome. Sustained released metoprolol reduces perioperative cardiac events in non-cardiac surgery but leads to more deaths and strokes. Steroids are probably not beneficial in either children with non-Haemophilus influenzae type $b$ bacterial meningitis, or in prophylaxis of acute respiratory distress syndrome (ARDS), but could be beneficial in the treatment of ARDS.
\end{abstract}

\section{Renal replacement therapy and acute kidney injury: route and intensity}

Parienti and co-workers [1] examined the effect of different catheter insertion sites for acute renal replacement therapy on the incidence of infection. Based on earlier findings, they hypothesized that use of the jugular site would reduce nosocomial events. The results of their randomized trial of 750 patients showed this was not the case. The rate of catheterization colonization with femoral access was comparable to that seen with jugular access: 40.8 versus 35.7 per 1,000 catheter-days $(p=0.31)$. Body mass index (BMI), however, did influence the association. In subjects with a BMI greater than 28.4, use of jugular rather than femoral access cut the risk of catheter colonization by $60 \%(p<0.001)$. With a BMI under 24.2, however, the opposite was true - jugular catheterization increased the risk by $110 \%(p=0.017)$. The incidence of haematomas was also higher in the jugular access group: $3.6 \%$ versus $1.1 \%(p=0.03)$.

A paper by Palevsky and co-workers [2] explored the optimal intensity of renal replacement therapy. Critically ill patients with acute kidney injury (defined as either injury or failure by the RIFLE criteria [3]) combined with either sepsis or additional dysfunctional organ systems were randomized to two renal replacement therapy intensity regimens. The highintensity strategy consisted of intermittent haemodialysis and sustained low-efficiency dialysis 6 times per week and continuous venovenous haemodiafiltration at $35 \mathrm{ml} / \mathrm{kg} / \mathrm{h}$. The lower-intensity strategy involved thrice-weekly haemodialysis/ sustained low-efficiency dialysis and continuous venovenous haemodiafiltration at $20 \mathrm{ml} / \mathrm{kg} / \mathrm{h}$. There was no difference in 60-day mortality between the two groups of 1,124 patients, and no difference in rates of recovery of renal function or prevention of other organ dysfunction. However, the incidences of hypotension and electrolyte disturbances were higher, and the duration of renal replacement therapy and hospital stay were longer in the patients in the high-intensity group.

Factor VII for acute intracerebral haemorrhage Following encouraging results from their phase 2 trial [4], Mayer and colleagues reported somewhat disappointing results from their definitive phase 3 trial on efficacy and safety of activated recombinant factor VII (rFVIla) for acute intracerebral haemorrhage [5]. In this trial, 841 patients with acute intracerebral bleed were randomly assigned to receive placebo, $20 \mu \mathrm{g} / \mathrm{kg}$ or $80 \mu \mathrm{g} / \mathrm{kg}$ of $\mathrm{rFVlla}$ within 4 hours of the onset of stroke. No significant difference was found between groups for poor clinical outcome (severe disability or death), which was the primary endpoint of the study. In fact, more patients in the $80 \mu \mathrm{g} / \mathrm{kg}$ group had poor outcome than patients in the $20 \mu \mathrm{g} / \mathrm{kg}$ or placebo groups - $29 \%, 26 \%$ and $24 \%$, respectively, although that was not statistically significant. Also, more patients in the $80 \mu \mathrm{g} / \mathrm{kg}$ group had serious thromboembolic arterial events compared to the placebo group ( $9 \%$ versus $4 \%, p=0.04$ ). Despite this, they showed that the growth of volume of intracerebral haemorrhage was reduced by $3.8 \mathrm{ml}(95 \%$ confidence interval $(\mathrm{Cl}) 0.9$ to $6.7 ; p=0.009)$ in the group receiving $80 \mu \mathrm{g} / \mathrm{kg}$. 
In the accompanying editorial [6], Dr Tuhrim comments that several lessons can be learned from this trial. Firstly, the dose of $\mathrm{rFVlla}$ of less than $80 \mu \mathrm{g} / \mathrm{kg}$ is ineffective. Secondly, doses larger than $80 \mu \mathrm{g} / \mathrm{kg}$ increase arterial thrombotic events without a corresponding decrease in haematoma growth. And finally, accomplishing a physiological goal may not necessarily lead to improvement in meaningful clinical outcome.

\section{POISE'd or not?}

An eagerly awaited POISE trial has finally been published [7]. The main objective of this multicentre randomized controlled trial was to investigate the effects of perioperative $\beta$ blockade. In this trial, 8,351 patients with, or at risk of, atherosclerotic disease were randomly assigned to receive either extendedrelease metoprolol succinate or placebo started 2 to 4 hours before non-cardiac surgery and continued for 30 days.

The results showed that for every 1,000 patients undergoing non-cardiac surgery, extended-release metoprolol would prevent 15 myocardial infarctions, 3 cardiac revascularization procedures, and 7 new cases of atrial fibrillation. However, that would be at the cost of 8 excess deaths, 5 strokes, 53 cases of clinically important hypotension, and 42 cases of bradycardia.

The authors suggested that current perioperative guidelines recommending beta-blockers to patients undergoing noncardiac surgery should reconsider their recommendations in light of the significant risks associated with the use of perioperative metoprolol.

In the accompanying editorial [8], Dr Fleisher and $\mathrm{Dr}$ Poldermans suggest that a lower dose of a beta blocker started a week before surgery rather than the 2 to 4 hours before, as in POISE - may still help. This editorial, however, was heavily criticised by Dr London in his editorial [9], mostly because both of the authors were heavily involved in writing guidelines for the perioperative $\beta$ blockade, and also because their opinion was almost entirely based on the DECREASE series [10] by Poldermans and colleagues, which were "mainly observational, done primarily only on vascular surgery patients and in only one country in the world". However, patients in these series were predominantly undergoing major vascular surgery and had documented wall motion abnormalities on dobutamine stress $\mathrm{ECHO}$, and, therefore, could possibly be considered higher risk than patients in the POISE study.

\section{Steroids for meningitis and acute respiratory distress syndrome}

The study by Mongelluzzo and co-workers [11] aimed to evaluate the relationship of adjuvant corticosteroid treatment with mortality and length of hospitalisation in children with bacterial meningitis.

The clinical setting was 27 tertiary care children's hospitals in the US where Haemophilus influenzae type $b$ meningitis is no longer prevalent. Between January 2001 and December
2006, a total of 2,780 children were discharged with bacterial meningitis as their primary diagnosis from these hospitals. Data regarding these hospitalisations were obtained and analysed. Propensity-adjusted Cox proportional hazards regression models stratified by age subgroups were used to analyse endpoints of time to death and time to hospital discharge.

Adjuvant corticosteroids (dexamethasone, hydrocortisone, or methylprednisolone intravenously on the first day of hospitalisation) were used in 248 children (8.9\%). The overall mortality rate was $4.2 \%(95 \% \mathrm{Cl} 3.5 \%$ to $5.0 \%)$, with a cumulative incidence of $2.2 \%$ at 7 days and $3.1 \%$ at 28 days after admission. Adjuvant corticosteroid therapy was not associated with reduced mortality in any age group. The hazard ratio $(\mathrm{HR})$ for children younger than 1 year was 1.09 (95\% Cl 0.53 to 2.24); the HR for children aged 1 to 5 years was $1.28(95 \% \mathrm{Cl}$ 0.59 to 2.78); and the HR for children older than 5 years was 0.92 (95\% Cl 0.38 to 2.25). Adjuvant corticosteroid use was also not associated with time to hospital discharge.

Limitations of the study include insufficient power to determine a difference in mortality with low case fatality rates and possibly unreliable discharge diagnosis. A prospective randomised controlled trial is necessary to determine the effect of steroids on mortality in children with bacterial meningitis.

The question of steroid use in acute respiratory distress syndrome (ARDS) has been a matter of hot debate for some years. The topic has again been revisited in a recent metaanalysis by Peter and colleagues [12]. The authors identified nine randomised trials. When administered before the onset of ARDS in four trials, steroids increased both the odds of developing ARDS (odds ratio 1.55, 95\% credible interval 0.58 to 4.05 ) and subsequently dying from ARDS (odds ratio $1.52,95 \%$ credible interval 0.30 to 5.94 ). Note that credible intervals crossed 1 and thus could not exclude a null effect.

However, when corticosteroids were administered for established ARDS (five trials) they seemed to decrease mortality (odds ratio 0.62 , credible interval 0.23 to 1.26 ) and increase number of days off mechanical ventilation. Although the probability of a positive effect was high (93.2\%), a null hypothesis could not be excluded.

As Adhikari and Scales pointed out in the accompanying editorial [13] "... for most doctors without strong prior beliefs, this systematic review provides moderately strong evidence for avoiding prophylactic corticosteroids in ARDS, and weak evidence for their therapeutic use. Such doctors will view these results as hypothesis generating and will await results of additional trials." Indeed, a multicentre, well-designed trial is probably long overdue.

\section{Competing interests}

The authors declare that they have no competing interests. 


\section{References}

1. Parienti JJ, Thirion M, Mégarbane B, Souweine B, Ouchikhe A, Polito A, Forel JM, Marqué S, Misset B, Airapetian N, Daurel C, Mira JP, Ramakers M, du Cheyron D, Le Coutour X, Daubin C, Charbonneau P; Members of the Cathedia Study Group: Femoral vs jugular venous catheterization and risk of nosocomial events in adults requiring acute renal replacement therapy: a randomized controlled trial. JAMA 2008, 299:2413-2422.

2. The VA/NIH Acute Renal Failure Trial Network: Intensity of renal support in critically ill patients with acute kidney injury. $N$ Engl $J$ Med 2008 0:NEJMoa0802639.

3. Ostermann M, Chang RW: Acute kidney injury in the intensive care unit according to RIFLE. Crit Care Med 2007, 35:1837$1843,1852$.

4. Mayer SA, Brun NC, Begtrup K, Broderick J, Davis S, Diringer MN, Skolnick BE, Steiner T; the Recombinant Activated Factor VII Intracerebral Hemorrhage Trial Investigators: Recombinant activated factor VII for acute intracerebral hemorrhage. $N$ Engl J Med 2005, 352:777-785.

5. Mayer SA, Brun NC, Begtrup K, Broderick J, Davis S, Diringer MN, Skolnick BE, Steiner T; the FAST Trial Investigators: Efficacy and safety of recombinant activated factor VII for acute intracerebral hemorrhage. N Engl J Med 2008, 358:2127-2137.

6. Tuhrim S: Intracerebral hemorrhage - improving outcome by reducing volume? N Engl J Med 2008, 358:2174-2176.

7. POISE Study Group: Effects of extended-release metoprolol succinate in patients undergoing non-cardiac surgery (POISE trial): a randomised controlled trial. Lancet 2008, 371:18391847.

8. Fleisher LA, Poldermans D: Perioperative $\beta$ blockade: where do we go from here? Lancet 2008, 371:1813-1814.

9. London MJ: Quo vadis, perioperative beta blockade? Are you "POISE'd" on the brink? Anesth Analg 2008, 106:1025-1030.

10. Poldermans D, Bax JJ, Schouten O, Neskovic AN, Paelinck B, Rocci $G$, van Dortmont L, Durazzo $A E$, van de Ven LL, van Sambeek MR, Kertai MD, Boersma E; Dutch Echocardiographic Cardiac Risk Evaluation Applying Stress Echo Study Group: Should major vascular surgery be delayed because of preoperative cardiac testing in intermediate-risk patients receiving beta-blocker therapy with tight heart rate control? J Am Coll Cardiol, 2006, 48:964-969.

11. Mongelluzzo J, Mohamad Z, Ten Have TR, Shah SS: Corticosteroids and mortality in children with bacterial meningitis. JAMA 2008, 299:2048-2055.

12. Peter JV, John P, Graham PL, Moran JL, George IA, Bersten A: Corticosteroids in the prevention and treatment of acute respiratory distress syndrome (ARDS) in adults: meta-analysis. BMJ 2008, 336:1006-1009.

13. Adhikari NKJ, Scales DC: Corticosteroids for acute respiratory distress syndrome. BMJ 2008, 336:969-970. 